Rev. High Pressure Sci. Technol., Vol. 7 (1998) 1481 1483

\title{
Application of Water Jet Chipping for Repair Works of Prestressed Concrete Bridges
}

\author{
F. Inoue*, I. Ozawa**, T. Tomii* and K. Ishimura*** \\ ${ }^{*}$ Technical Research Institute, Obayashi Corporation, Kiyose-city, Tokyo 204, Japan \\ ** Civil Engineering Technical Department, Obayashi Corporation, Bunkyo-district, Tokyo 113, Japan \\ *** Japan Highway Public Corporation, Kanazawa-city, Ishikawa 920, Japa
}

\begin{abstract}
Concrete structures which need repair and maintenance work because of salt damage have recently increased in number. Hence, in maintenance management, it is necessary to chip off the existing concrete surface and to cut away salt damaged areas efficiently. Until now, this has depended primarily on manual operation by using pick hammers and the like. However, work efficiency tended to be low due to the extremely poor working environment that offen involved heavy vibration and noise, and it has been shown that the impact of the chipping operations has adverse quality effects in undamaged sections. Therefore, the development of a new method was strongly demanded. An automated chipping system to cut away the salt damaged areas by utilizing high pressure water jets has been developed and applied to actual reinforcing work. This report details the development of an automatic water jet chipping method applied to large-scale reinforcing work on a salt damaged pre-stressed concrete bridge, and also describes the results of on-site implementation and improvement.
\end{abstract}

[Water Jet Technology, Automated Construction Robot, Concrete Chipping, Concrete Bridge Maintenance]

\section{Introduction}

Numerous concrete bridges and other reinforced-concrete structures along the coast of the Sea of Japan are damaged by salt that is carried inland by seasonal winds and penetrates the concrete, corroding the steel reinforcing bars. It is extremely difficult to prevent and repair such damage. The results of a survey of bridges conducted by the Ministry of Construction in 1982 and 1983 revealed superstructure damage caused by salt occured in as many as $24 \%$ of all concrete road bridges within $500 \mathrm{~m}$ of the seacoast on the Japan Sea side of the Hokuriku, Tohoku, and Hokkaido region. The effects of seasonal winds are particularly severe on these three coastlines. It is assumed that this figure has increased since the survey was conducted. Salt penetrates this damaged concrete and accumulates inside it, and in some cases, repeated partial repair work was not able to halt the progress of the corrosion and deterioration of the concrete.

The Tedori River Bridge on the Hokuriku Expressway is an eight-span prestressed concrete bridge with a continuous-hinged rigid-frame very close to the mouth of the Tedori River in Ishikawa Prefecture. Because partial repairs and surface-coating measures, etc., carried out to deal with salt damage to the bridge have failed to control advancing corrosion, large-scale repair and reinforcement work was planned. This work, which entails the chipping and removal of damaged concrete and salt-permeated concrete from the entire bottom surface of the superstructure of the bridge and its replacement with mortar, will be performed over a surface area of 16,000 square meters (see Fig. 1).

\section{History of Using the Water Jet Chipping Method}

Until now, the chipping phase of such repair work has been performed by manual laborers using pick hammers and the like, but the working environment was very poor as a result of the dust raised and the vibration generated. In addition, when work is performed on a bridge, workers are almost always facing upwards, and directly exposed to falling fragments of chipped concrete. These conditions significantly reduce execution efficiency and safety.

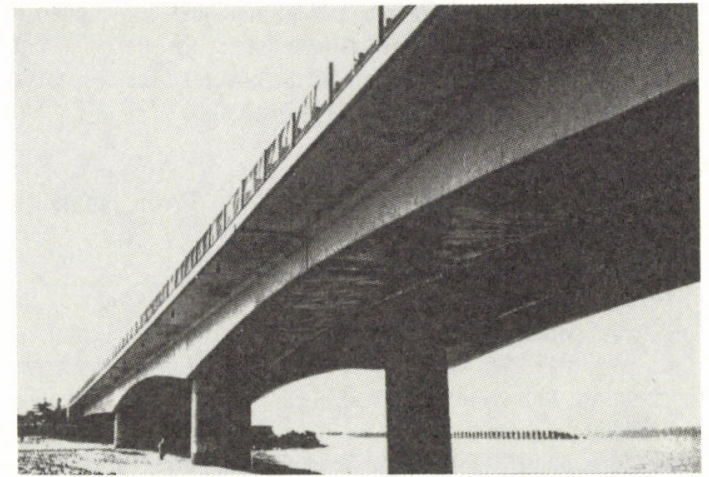

Fig 1 Tedori river bridge repaired by water jet method.

The water jet chipping method was developed for such repair works. When the development of the new system began, the goal was to obtain the following benefits:

(1) This method, in which concrete is chipped from a concrete surface by moving a nozzle discharging water under super-high pressure across the surface, would be a relatively simple way to automate this work.

(2) Using water-jet chipping, it would be possible to control the nozzle to remove the concrete from behind the steel reinforcing bars without damaging them.

(3) The execution capacity would be increased to many times what is possible with the manual method.

Based on these features, the water jet chipping method was judged to be a suitable technique for use in large-scale repair work, and will be adopted as a general-purpose method to meet future demand.

\section{Components of the Chipping System}

Principal components of the chipping system consist of the high pressure water generator, chipping robots, and water purification equipment. 
Fig. 2 shows a schematic outline of the system.

(1) High Pressure Water Generator

This device is a hydraulic booster-type high pressure pump that provides a discharge volume of between 10 and $50 \mathrm{l} / \mathrm{min}$ and a discharge pressure of approximately $250 \mathrm{Mpa}$.

(2) Chipping Robots

The chipping robots have a nozzle unit to eject the water jet and a nozzle movement device. The chipping depth and chipping shape shown in Fig. 3, are controlled by setting the following functions: (1)nozzle head orifice diameter, (2)angle of the waterjet, (3)standoff distance, (4)nozzle rotation speed, (5)nozzle feed pitch and (6)nozzle feed rate.

Each chipping robot is specially designed for a specific part of the bridge. The values preset for each of its functions vary according to the concrete strength, aggregate, shape of the bridge to be chipped, and are adjusted for each execution in accordance with basic experimental data obtained from laboratory studies.

(3) Water Purification System

Slurry chipped concrete fragments and particles in the waterjet water are recovered by a muck collector installed under the robot. The concrete fragments are accumulated for industrial waste treatment. Following $\mathrm{pH}$ adjustment of the slurry, which becomes alkaline from the effects of the concrete, the suspended particles are deposited, and the fluid is discharged.

\section{Results of the Work}

The repair work on the right lanes of the Tedori Bridge has been completed. Results are as follows;

(1) Chipping Work

Because the bottom surface of the bridge was chipped, the work was performed without stopping traffic. The chipping work performed by the robot and the chipping procedure flowchart are shown in Fig.4 and Fig.5 respectively.

(2) Chipping Capacity

Approximately $4,000 \mathrm{~m}^{2}$ (to a depth of about $50 \mathrm{~mm}$ ) of the surface was completely chipped in just under six months. As the first application of the method, the planned chipping surface area per hour was set at $1.6 \mathrm{~m}^{2}$ at the beginning of the development project. As the work progressed, various functions were adjusted and improved, and at the same time the operators gradually learned to use the system more skillfully. This increased the capacity of the system to $2.0 \mathrm{~m}^{2} /$ hour. The preset values for the functions are shown in Table 1.

(3) Chipping Precision

The chipping depth precision is shown in Fig.6. It was satisfied to about $+/-10 \mathrm{~mm}$ at a depth of $50 \mathrm{~mm}$. The graph, based on data from laser measurements, shows values obtained by subtracting the measured value following chipping from the measured value prior to chipping.

\section{Problems and Improvements}

Following the completion of inbound lane work, a variety of problems during execution were revealed. For example, there was a tendency for a deep groove to form at the boundary of the chipping surface adjoining the movement lanes of the nozzle. It was necessary to perform more water treatment than anticipated due to using polymer water. So, the cost was much too high.

Consequently, in the outbound lane work, the following improvement to the system were carried out.

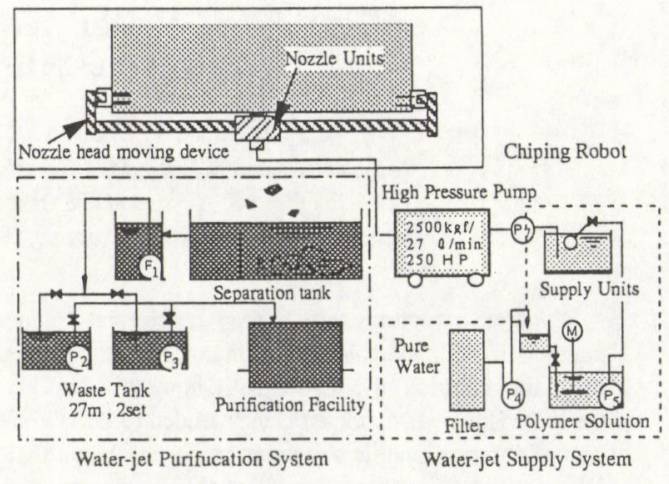

Fig.2 Schematic outline of chipping system.

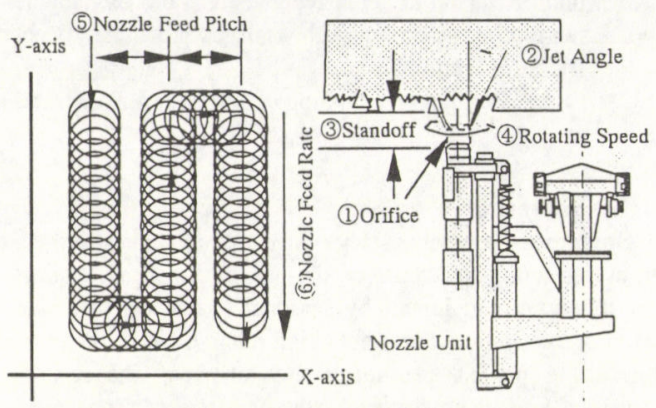

Fig.3 Chipping robot and its control functions.

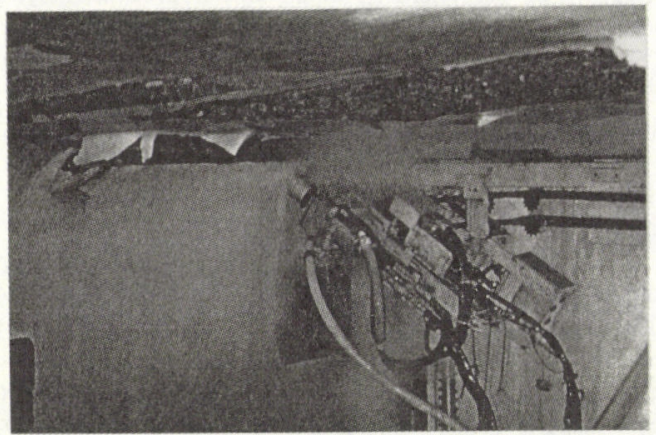

Fig.4 Actual chipping work by using water jet.

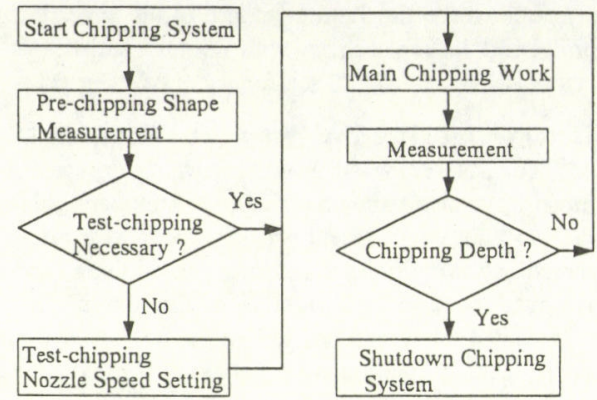

Fig. 5 Chipping procedure flowchart. 
(1) Use of pure water and improved orifice

It was discovered that replacing the polymer-added water with pure water caused a decline in the water jet's energy accompanied by a decrease in its capacity, and the spread of the water jet stream. Therefore, the flow rate of water-jet was increased to improve its capacity. In addition the spreading of the water-jet stream was dealt with by improving the long tapered of the orifice at the tip of the nozzle.

(2) Improvement of feed pitch

While the execution capacity was improved, the irregularities of the chipped surface increased, a deep groove was clearly visible at the boundary of the adjoining chipping surface. To deal with the irregularities in the chipped surface, it is necessary to control the nozzle movement mechanism so that the water jet's chipping energy was uniformly applied to the concrete chipping surface. Testing confirmed that it was possible to control the amount of chipping performed by changed the nozzle movement mechanism. In the way, in order to reduce the groove and irregularities through overlapping the chipping lanes.

(3) Change of jet angles

As it would be difficult to control the chipping range when the flow volume is high under the effects of scattering of the concrete quality, the angle range was set between $0 \sim 15$ degrees However, as testing confirmed that decreasing the angle of the water-jet reduces the execution capacity, it was forecast that the execution performance would decrease when chipping is performed behind the reinforcing bars.

Table 2 shows the improvements described above. This data was obtained from the results of laboratory testing using specimens with a compressive strength of approximately 45 $\mathrm{N} / \mathrm{mm} 2$ and dimensions of $1,000 \mathrm{~mm}^{*} 2,000 \mathrm{~mm} * 200 \mathrm{~mm}$.

The greatest execution capacity was obtained following improvement stage 1 , but there was a tendency for the deepest groove to occur at the boundary of the adjoining concrete chipping lanes, and the irregularities were large: problems that would interfere with the application of the method. Following improvement stage 2, double of execution capacity that achieved by the upward lane work was realized, and as Fig.7 indicates, the condition of the chipping surface was good.

In the results of a test of the improvements, the stage- 2 method was adopted for work on the outbound lane of the Tedori River Bridge. The design and assembly of the robots have been completed, and execution has just begun. The machine for the bottom-surface is already running, and as Fig. 8 shows, the state of the chipping is good.

Now, the chipping work on the outbound lane is continuing and its completion is scheduled for the end of August in 1997.

\section{Conclusions}

Although the equipment used for the inbound lane work of the system is virtually identical to that used for the outbound lane work, its performance is far superior. However, because the improved robots are brand new, additional data on their operating characteristics and the quality of their work will be collected in order to improve this technology further.

The authors would like to conclude this report by thanking everyone involved in the development, improvement, and field application of the water-jet chipping system.

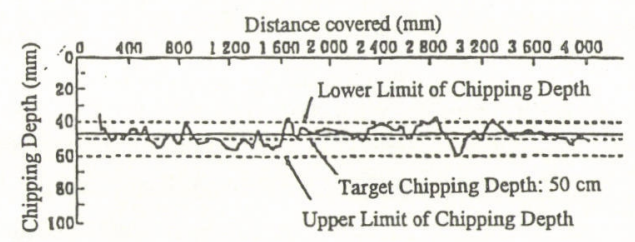

Fig.6 Chipping depth recision.

Table 1 Improvement of preset value of chipping robot.

\begin{tabular}{|c|c|c|c|}
\hline Item & $\begin{array}{c}\text { Upward lane } \\
\text { Work }\end{array}$ & \begin{tabular}{|c|} 
Improvement \\
1 \\
\end{tabular} & $\begin{array}{c}\text { Improvement } \\
2 \\
\end{array}$ \\
\hline Orifice Shape & Short Tapered & Long Tapered & \begin{tabular}{|l} 
Long Tapered \\
\end{tabular} \\
\hline Nozzle Movement & Rotating & Rotating & $\begin{array}{c}\text { Rotating and } \\
\text { Vibration }\end{array}$ \\
\hline Fluid Condition & Polymer & Pure & Pure \\
\hline Pressure (MPa) & 240 & 206 & 245 \\
\hline Flow Rate $(/ / \min )$ & 24 & 54 & 50 \\
\hline Jet Angle (degree) & 25 & 35 & 0 \\
\hline RotatingSpeed (rpm) & 30 & 35 & 210 \\
\hline Rotating Radius (mm) & 20 & 80 & 20 \\
\hline Feed Rate (mm/min) & 300 & 300 & 4200 \\
\hline Chipping Pitch (mm) & 110 & 270 & 35 \\
\hline Chipping Depth (mm) & 57 & 55 & 54 \\
\hline Execution Capacity $\left(\mathrm{m}^{2} \mathrm{~h}\right)$ & 2.0 & 4.9 & 4.2 \\
\hline Surface Condition & Grooves & $\begin{array}{c}\text { Large } \\
\text { grooves }\end{array}$ & No groove \\
\hline
\end{tabular}

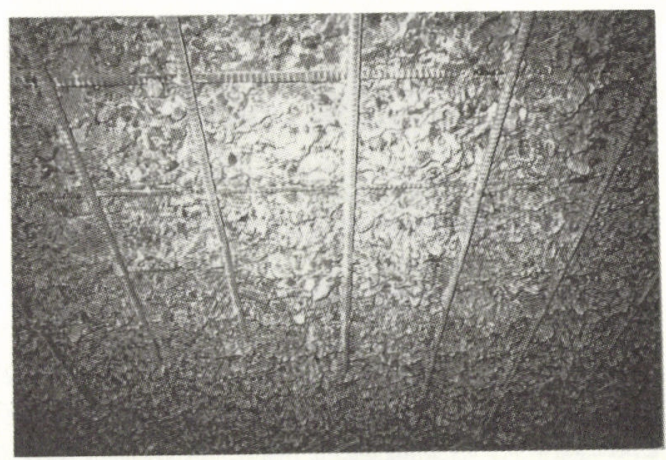

Fig.7 Condition of the chipping surface.

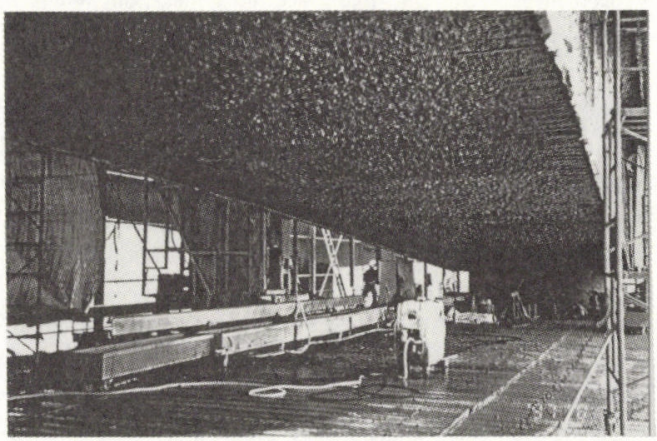

Fig. 8 Whole state of the chipping surface. 